\title{
Guillermo Porras \\ Muñoz. Destacado \\ HISTORIADOR \\ CHIHUAHUENSE
}

DIZÁN VÁZQUEZ LOYA ${ }^{1}$

\section{RESUMEN}

Se presenta la vida y obra de Guillermo Porras Muñoz (19171988), uno de los más destacados historiadores chihuahuense, especialmente del período colonial, como un homenaje a su memoria y como una forma de darlo a conocer a estudiantes e historiadores jóvenes. Se ofrece, además, una lista completa de su obra, que puede ser de utilidad para los investigadores.

Palabras clave: Porras Muñoz; historia; Chihuahua; Nueva Vizcaya

\section{1. ${ }^{\mathrm{A}}$ PARTE: BIOGRAFÍA}

\section{SU IMPORTANCIA}

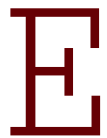

n el panorama historiográfico de Chihuahua, que cada vez más se enriquece con la aportación de valiosos historiadores, se destaca uno que puede ser considerado el más importante, al menos para el periodo colonial en el que centró su atención. Su obra sobre esa época sigue siendo de consulta imprescindible. Se trata de Guillermo Porras Muñoz. Mucho se ha escrito sobre él y se le ha valorado en su justa dimensión, pero

1 Universidad Autónoma de Ciudad Juárez, México. Correo electrónico: divazque@uacj.mx 
creo que es justo que ahora encuentre también un espacio en las páginas de Chihuahua Hoy, obra colectiva destinada a temas relativos de nuestro estado. Le dedicamos, pues, estas páginas llenas de admiración y respeto por su persona y su obra.

\section{SUS RAÍCES}

Fue solo por un accidente histórico que Guillermo Porras Muñoz naciera en El Paso, Texas, el 22 de julio de 1917, pero sus raíces familiares estaban en Parral desde hacía muchas generaciones. Por eso nadie nos puede quitar el honor de tenerlo como paisano, como chihuahuense, y él mismo se consideró siempre chihuahuense de pura cepa.

Fueron los avatares de la revolución los que arrojaron a sus padres a esa ciudad fronteriza de Estados Unidos, que los acogió, como lo ha hecho muchas veces con tantos refugiados y exiliados políticos de México, sin importar el bando al que pertenecieran.

Manuel Porras Mendoza, su padre, había nacido en Parral en $1878,{ }^{2}$ fue químico de profesión y en la primera década del siglo xx estaba involucrado políticamente con el régimen de Porfirio Díaz. De 1909 a 1911 fue diputado a la xxVII Legislatura local por Allende, y de 1908 a 1911 fungió como jefe político del distrito Jiménez. Fue precisamente en Jiménez donde conoció a María Muñoz Chávez, nacida en esa población, con la que contrajo matrimonio.

A fines de 1911 o principios de 1912, poco después de iniciada la revolución y por causa de las acciones violentas de Pancho Villa en Parral, Manuel y María, recién casados, tuvieron que exiliarse en El Paso, a donde fueron a dar también otros apellidos parralenses como los Chávez Aizpuru, los Iwoinsky Artalejo, los Arras Rodríguez, los Jurado Torres, los Martínez López, los Matheus Aizpuru y otros. Con Manuel Porras Mendoza iba también su

2 Hijo de Guillermo Porras y María de Jesús Mendoza. Los hijos de este matrimonio fueron Guillermo, Manuel, Guadalupe y María. Al enviudar Guillermo, se casó por segundas nupcias con Rosalía Caballero. El padre de este Guillermo, o sea el bisabuelo de Guillermo Porras Muñoz, llamado Manuel Porras, fue miembro, con el grado de alférez, del escuadrón auxiliar de infantería que comandaba el general Carlos Pacheco en el año de 1843 (Treviño, Salvador, Novedades de Chihuahua, 1989). 
hermano Guillermo, famoso abogado que fungiera como secretario particular del gobernador Enrique C. Creel y que llevaba los asuntos jurídicos del general Luis Terrazas, además de incursionar en el campo de la historia, ${ }^{3}$ afición que, tal vez, supo transmitir a su sobrino y tocayo, junto con la vocación de abogado. En El Paso nacieron los cuatro hijos de Manuel y María: Rosalía, Manuel, María Luisa y nuestro Guillermo, en este orden.

Los Porras pertenecían a una de las familias más antiguas avecindadas en la Nueva Vizcaya. Diego de Porras fue uno de los fundadores y primeros pobladores de Real de San José del Parral al tiempo de su fundación (1631-1632). La casa familiar de los Porras estuvo durante tres siglos en una esquina de la plaza, calle de por medio, frente a la parroquia de San José. A don Diego se debe la introducción en Parral de la devoción a la Virgen de la Soledad, tradicional en la familia desde sus orígenes en España. Precisamente en la península fue donde Guillermo Porras rastreó su ascendencia y descubrió que la rama mexicana de la familia Porras desciende del caballero don Rodrigo de Porras, originario de la villa de Valdeporras, en la provincia de Burgos, en el reino de Castilla, del cual fue conquistador y cuya descendencia quedó integrada en el marquesado de Chiloeches. ${ }^{4}$

Por parte de su madre, los Porras Muñoz entroncan con la familia Muñoz, de Guadalajara, en el reino de la Nueva Galicia, y con la familia Chávez, descendiente de los conquistadores del reino del Nuevo México y fundadores de varias villas y poblados del actual estado de Chihuahua.

3 Publicó en 1946 Hidalgo del Parral. Reseña histórica. Edición del autor. Chihuahua.

4 El investigador jesuita Salvador Treviño ahonda todavía más en el origen de los Porras en Chihuahua y nos dice que esta familia "hunde sus orígenes hasta fines del siglo XVI en el antiguo Valle de San Bartolomé, hoy Valle de Allende. El fundador de esta estirpe es el rico estanciero y ganadero Don Luis de Salvatierra, originario de la Ciudad de México, hijo de Don Juan de Salvatierra y de Doña Isabel de Porras. La descendencia preferirá el apellido materno al paterno, aunque a veces los varones de esta familia eran conocidos como Salvatierra de Porras". En el siglo xvII el linaje de los Porras está representado por don Antonio Porras, originario de San Bartolomé, que moraba en el río San Pedro, cerca de Satevó, hijo de Salvador Porras e Inés Enríquez (Treviño, Salvador, 1988; 1989). 


\section{SU FORMACIÓN ACADÉMICA}

Guillermo hizo sus primeros estudios en la Vilas School, y los secundarios en El Paso High School. En 1934 la familia regresó a Chihuahua y Guillermo, de diecisiete años, se inscribió en el Instituto Científico y Literario para estudiar la preparatoria. Después partió a la Ciudad de México en 1936, a los diecinueve años, para cursar la carrera de abogado en la Escuela Libre de Derecho, en la que se recibió en 1943. En México vivía en una casa de huéspedes, en la calle de Chiapas número 103, donde se hospedaban otros muchachos de Chihuahua, que llegaron a ser también exitosos profesionistas y empresarios, entre ellos, Mario y José González Múzquiz, Francisco y Carlos Aguirre, Antero Jiménez, José Manuel Falomir y Jesús Roberto Durán.

Mientras estaba en México, su interés por la historia lo llevó a hacer estudios en el Instituto Nacional de Antropología e Historia (INAH), siendo allí discípulo de connotados historiadores como Alfonso Caso, Pablo Martínez del Río y Rafael García Granados. Se inscribió también en 1941 en El Colegio de México, fundado ese año, como alumno del Centro de Estudios Históricos. Su ansia insaciable de saber lo llevó también a tomar clases en la Facultad de Filosofía y Letras de la unAM, interesándose, entre otras materias, en la historia de España, historia del arte y, muy especialmente, en la historia virreinal.

Después de diez años en la Ciudad de México, y sin haber regresado a Chihuahua más que de visita, provisto de una beca por la Junta de Relaciones Culturales del Ministerio de Asuntos Exteriores de España, Billy —apodo con el que se le conocía desde su infancia en El Paso y que conservaría siempre- partió a España en 1946. En este momento de su vida se da, al parecer, un gran viraje, pues conoce el Opus Dei ${ }^{5}$ y se decide ingresar en esa organización católica apenas unos meses después de haber llegado a España. En 1948 se doctoró en derecho civil en la Universidad de

5 El Opus Dei es una organización católica, a menudo controversial, fundada el 2 de octubre de 1928 por el sacerdote español Josemaría Escrivá de Balaguer, y transformada en prelatura personal por el papa Juan Pablo II en 1982, quien también canonizó al fundador. 
Sevilla, interesándose especialmente en historia del derecho que estudió con prominentes profesores de esas materias, como Antonio Muro Orejón, especialista en derecho indiano. También cursó materias de historia de América en la Universidad Internacional Menéndez Pelayo y en la Universidad de La Rábida. En esta última fue profesor de dicha materia en 1949 y 1950, y volvería a serlo en 1963. En ese tiempo, de 1947 a 1951, se dedicó intensamente a investigar en el Archivo General de Indias.

En 1961 volvería a España, esta vez a la Universidad de Navarra, para hacer un doctorado en derecho canónico, grado que obtuvo en 1964.

\section{SU VOCACIÓN RELIGIOSA}

Como dijimos, poco después de su llegada a España, Guillermo entró en contacto con el Opus Dei y pidió su admisión como miembro numerario, cosa que le fue concedida el 25 de julio de 1947, en Madrid. La inmensa mayoría de los miembros del Opus Dei son laicos, pero este cuenta también con su propio clero y Guillermo decidió, de acuerdo con sus superiores, convertirse en sacerdote, con gran sorpresa para su familia, que siempre lo había soñado como un brillante abogado, siguiendo el ejemplo de su tío. Su ordenación, junto con otros miembros del Opus Dei, se verificó en Madrid el 1. ${ }^{\circ}$ de julio de 1951. Fue el primer sacerdote mexicano del Opus Dei. Regresó inmediatamente a México y el 25 de julio celebró su primera misa en la catedral de Chihuahua, asistido por el vicario general monseñor José de la Paz García y por el padre José Martínez Cabrera, S. J., teniendo como padrinos a sus padres y a su tío Guillermo con la esposa de este, Carmen Hirigoity, ${ }^{6}$ quienes eran, además, sus padrinos de bautismo.

El padre Porras tuvo siempre una gran admiración por el fundador del Opus Dei. Así nos narra él mismo su primer encuentro con Escrivá de Balaguer:

6 Estampa conmemorativa de ese evento. 
Lo conocí hace 28 años [en 1947]. Yo hacía un curso en la Universidad Menéndez y Pelayo, en Santander, cuando un socio de la Obra me dijo que el Padre - así quiso siempre que le llamáramos sus hijos-, estaba en Bilbao y que se le podía visitar. Con un amigo tomé el tren ese mismo día... Pensaba en el protocolo que suele seguirse cuando se va a visitar a un personaje. Llegamos a la residencia de Avando y nos dijeron que el Padre estaba en el despacho del director. Sin esperar el elevador, subimos corriendo y entramos. El Padre estaba de pie en el balcón, espaldas a la calle, charlando familiarmente con un grupo de ocho o diez universitarios... A través de los años me tocó estar con él muchas veces en Madrid, en Molinoviejo, en Pamplona, en Roma, en México y, últimamente, en Guatemala (Porras Muñoz, 1975).

\section{CAPELLÁN DE UNIVERSITARIOS}

En octubre de 1951 Porras Muñoz se trasladó a Estados Unidos para promover en ese país el Opus Dei. Radicó un año en Chicago y luego pasó al estado de Massachusetts, donde el arzobispo de Boston lo nombró capellán de los estudiantes católicos de la Universidad de Harvard, en Cambridge, cargo en el que permaneció de 1953 a 1960. En esa universidad gestionó y logró que se instituyera la "Cátedra Chauncey Stillman de Estudios Católicos". Luego prestó el mismo servicio pastoral en Washington y Nueva York, con algunas temporadas en Canadá.

En 1961 dejó Estados Unidos para dirigirse a la Universidad de Navarra, donde hizo el doctorado en derecho canónico. A su regreso de España, en el verano de 1964, regresó a Harvard a continuar con su actividad pastoral con los universitarios, y, al mismo tiempo, atendía también a los del Instituto Tecnológico de Massachusetts. Alrededor de 1970 se trasladó a la Ciudad de México, donde fue nombrado capellán de la Residencia Universitaria Panamericana (RUP) dirigida por el Opus Dei, en Hortensias 238, colonia Florida. A partir de dicho año la capital de la república habría de ser su lugar de residencia y trabajo durante veintitrés años, hasta su muerte. En ese periodo impartió también algunos 
cursos de teología en la Universidad Panamericana y en el Instituto Panamericano de Alta Dirección de Empresas (IPADE), y pasaba largas horas trabajando en sus escritos de historia en el Centro de Estudios de Historia de México, creado por la empresa Condumex.

\section{SU PASIÓN POR LA HISTORIA}

Guillermo Porras Muñoz fue doctor "in utroque iure", es decir, en derecho civil y canónico, y se dedicó, como actividad principal, a la orientación pastoral de los universitarios. Sin embargo, la razón principal por la que será recordado siempre es por su contribución a la historiografía de nuestro país. Se podría decir que la historia fue su verdadera vocación académica, solo superada por su vocación sacerdotal, y utilizó en el estudio de la historia las herramientas invaluables que le proporcionó su excelente preparación en el campo del derecho, la filosofía y la teología, y, desde luego, la historia.

Sin haber adquirido un grado académico en historia, su preparación en ese campo fue, sin embargo, excelente. Fue historia lo que cursó en el recién fundado El Colegio de México y en el INAH, al tiempo que cursaba la licenciatura en derecho. Igualmente, sus cursos en las universidades de Sevilla, Menéndez Pelayo y de La Rábida, siendo en esta última profesor de historia de América. Hay que tener en cuenta también la formidable capacitación que obtuvo en esa otra "universidad" que fue el Archivo General de Indias de Sevilla, en el que investigó durante cinco años seguidos y muchas otras veces en el transcurso de su vida, lo mismo que en el Archivo General de la Nación y en otros importantes acervos.

Con una vocación y una actividad superpuestas a todo lo demás que hacía, su dedicación al estudio de la historia consumió una gran parte de su tiempo y así nos dejó una notable producción en este campo: por lo menos nueve libros y folletos, y unos sesenta artículos, publicados la mayor parte en revistas de alta calidad científica. Su contribución principal a la historiografía mexicana se ubica, como es bien sabido, en el periodo colonial y en la historia de las instituciones jurídicas novohispanas. Su aportación a 
la historiografía en estos temas es fundamental. También nos dejó más de treinta títulos de temas no históricos, principalmente religiosos, en los que se revela no solo su profunda fe, sino también su gran calidad humana no exenta de cierta dosis de fino humor.

Su pasión por la historia comenzó muy temprano. Historiador precoz, sus primeros trabajos de historia son algunos artículos y reportajes publicados en The Tatler, semanario de los alumnos de El Paso High School, entre 1933 y 1934. Tenía apenas dieciséis años. Del periodo de 1933 a 1937 son también sus artículos publicados en la revista Southwest, de El Paso.

De ahí en adelante no dejaría de escribir, combinando sus estudios de derecho y sus diversas ocupaciones pastorales con la publicación de artículos y libros cada vez más sustanciosos. Durante su carrera de abogado publicó cuatro artículos en la revista Divulgación Histórica, entre 1941 y 1943.

Fue en esta época de estudiante de derecho cuando Guillermo se volcó decididamente hacia los archivos como fuente primaria indispensable para la investigación histórica. Como podía, se daba tiempo para pasar largos ratos en el Archivo General de la Nación para ponerse en contacto con los datos originales de nuestra historia norteña.

Él mismo narró en 1986, con ocasión de su ingreso en la Academia Mexicana de la Historia, cómo le nació el interés por los archivos:

En 1936, hace 50 años -tenía entonces 19 años - fui motivado por un artículo sobre Chihuahua, que apareció en un semanario (de la ciudad de México) y que empezaba diciendo: "Chihuahua, como las mujeres honradas, no tiene historia” ¿Cómo es posible que no tenga historia? Me pregunté. Al día siguiente fui a la Biblioteca Nacional y, efectivamente, no encontré ningún libro de Historia de Chihuahua... Decidí que era necesario investigarla y escribirla, y me fui al Archivo General de la Nación. La señora Mercedes Osorio me orientó sobre los fondos del archivo, pedí el primer tomo del ramo de Provincias Internas y me puse a leer. Al otro día compré fichas y un fichero 
para ir recogiendo los datos que me interesaban. Me convertí en un asistente asiduo.

Porras Muñoz, finalmente, no escribió una historia general de Chihuahua, pero sí aportó elementos imprescindibles para escribirla.

En esa misma ocasión afirmó también en una entrevista que le hicieron:

La historia de México tiene grandes lagunas. Es aún mucho lo que hay que hacer para cubrirlas, para ello hace falta un mayor apoyo a los historiadores y un presupuesto adecuado para el rescate de los archivos que aún están sin catalogar... No tiene caso afirmar lo que ya se ha dicho tantas veces sin ninguna base. Es necesario investigar, hurgar en los archivos, en las bibliotecas, para reconstruir una realidad... Ejemplo de esto es lo que se dice del clero secular, es decir, el diocesano, en la evangelización de la Nueva España. La mayoría de los historiadores del siglo XVI afirman que este clero no tuvo una gran participación en esta tarea, a diferencia de las órdenes religiosas como los franciscanos, dominicos y agustinos...

Porras Muñoz utilizó este ejemplo a propósito de su discurso de ingreso en la Academia, que versó precisamente sobre El clero secular y la evangelización de la Nueva España.

A lo largo de su vida, el doctor Porras llegó a elaborar unas setenta mil fichas, escritas en muy diversos archivos y bibliotecas del mundo. No pocos de sus artículos consisten en la presentación de valiosos documentos que él rescató de los archivos, paleografió y publicó enriquecidos con eruditas introducciones y notas.

En su tiempo de estudiante de derecho, Guillermo trabó amistad con el insigne historiador duranguense Atanasio G. Saravia y pasó muchas horas con él "consultando libros y documentos y cambiando impresiones. A pesar de la diferencia de edades se estableció entre ellos una relación de afecto y aprecio mutuos", según testimonio de Amelia, hija de don Atanasio (Saravia de Farrés, 1989). 
Una vez terminada la carrera, el joven abogado permaneció en la Ciudad de México y desde allá colaboraba con sus artículos de historia, primero para la Revista Chihuahua y luego para el Boletín de la Sociedad Chihuahuense de Estudios Históricos. En la primera, en el solo año de 1944 colaboró con cinco artículos. En el mes de noviembre de ese mismo año, respondiendo a la invitación de León Barrí, que estaba entonces en México, Guillermo se incorpora a la Sociedad Chihuahuense de Estudios Históricos formando el Comité Histórico de la Ciudad de México, dependiente de la misma. Integraron dicho comité Atanasio G. Saravia, como presidente; Lorenzo Arellano Schetelig, como secretario; Guillermo Porras Muñoz, como tesorero; el coronel Manuel Vázquez, el ingeniero Luis G. Franco y la señorita Lucila Muñoz Ochoa como primero, segundo y tercer vocales, respectivamente. Guillermo comenzó a mandar artículos al Boletín de la Sociedad Chihuahuense de Estudios Históricos, que fueron publicados en número de seis entre 1945 y 1947. Fue probablemente en este periodo de su vida en México cuando tomó un seminario sobre The Mexican Frontier, dirigido por el famoso historiador norteamericano doctor Herbert Eugene Bolton, especialista en la historia de la expansión hispánica en Norteamérica y que, para ese entonces, ya era profesor emérito de historia en la Universidad de California en Berkeley.

Fruto de sus investigaciones en el Archivo General de Indias son los artículos que publicó en diversas revistas científicas españolas entre 1947 y 1952. En ese tiempo, además, participó en importantes congresos sobre historia hispanoamericana.

Su permanencia en Estados Unidos, de 1951 a 1961, aparentemente fue una larga pausa en su producción como historiador, al menos en cuanto a publicaciones, pues su bibliografía no registra ningún título en ese periodo. Es posible que tocara esos temas en la colaboración que tuvo en ese tiempo con la New Catholic Encyclopedia, que fue publicada en Washington en 1967. Es también muy probable que, haciendo uso del riquísimo acervo de notas de archivo que poseía, comenzara en esta época a redactar la más importante de sus obras: Iglesia y Estado en Nueva Vizcaya (1562-1821). Esta obra fundamental la escribió, finalmente, en 
Pamplona, como tesis para su doctorado en derecho canónico en la Universidad de Navarra, y fue publicada por la misma universidad en 1966 . $^{7}$

El último periodo de su vida, que fue su larga permanencia en la Ciudad de México, y que va de 1965 hasta su muerte en 1988, fue el más fecundo, si no en cantidad de títulos, sí en calidad, pues fueron el fruto de su madurez como investigador: veinticuatro títulos de libros, entre ellos, La frontera con los indios de Nueva Vizcaya en el siglo XVII, publicado en 1980, ${ }^{8}$ así como artículos publicados en prestigiadas revistas de México y España, como el Boletín del Archivo General de la Nación, Anuario de Estudios Americanos, Estudios de Historia Novohispana, Revista del Instituto de Investigaciones Históricas, lo mismo que colaboraciones en diversos libros. Se pasaba largas horas investigando en el Archivo Histórico de Condumex. ${ }^{9}$ A esta época pertenecen también los veinticuatro títulos que publicó sobre temas religiosos. ${ }^{10}$

\section{SU RELACIÓN CON CHIHUAHUA}

Guillermo Porras Muñoz vivió en Chihuahua solo en un periodo muy corto de su vida, siendo adolescente. Sin embargo, sus lazos, tanto intelectuales como afectivos, con su tierra no se interrumpieron jamás. Chihuahua estuvo siempre presente en su vida por sus continuas investigaciones sobre la Nueva Vizcaya y por el afecto que lo unía con sus familiares más cercanos, hermanos y sobrinos, que vivían en el estado. Ya hemos mencionado sus colaboraciones en revistas de Chihuahua y su membresía en la Sociedad Chihuahuense de Estudios Históricos desde la Ciudad

7 Josefina Muriel, que en algún tiempo fuera compañera de estudios del padre Porras en España, hizo una reseña de esta obra; véase: http://www.ejournal.unam.mx/ehn/ ehn03/EHN00309.pdf (abril de 2018). María del Carmen Velázquez (de El Colegio de México) también la reseñó junto con La frontera con los indios de Nueva Vizcaya en el siglo xVII, y El gobierno de la Ciudad de México en el siglo XVI. Véase en http://www. aleph.org.mx/jspui/bitstream/56789/25192/1/38-149-1988-0143.pdf (abril de 2018).

8 Reseña de Ernesto de la Torre Villar en Estudios de Historia Novohispana, Vol. 9, n. ${ }^{\circ}$ 9 (1987), pp. 240-242.

9 Que después tomó el nombre de Centro de Estudios de Historia de México Carso.

10 Véase la bibliografía completa de Porras Muñoz en la segunda parte de este ensayo.

Chinuahua Hoy, aÑo i6, Núm. I6 (ENERo-Diciembre, 2018) 
de México. Hay que añadir que desde Sevilla mandó en 1947, por lo menos, dos interesantes artículos que se publicaron en $E$ l Correo de Parral.

Siempre interesado en Chihuahua, el 12 de agosto de 1964 le escribe desde Nueva York a don José Carlos Chávez para proponerle a la Sociedad Chihuahuense de Estudios Históricos reconstruir el archivo que se perdió en el incendio, microfilmando los documentos relativos a Chihuahua existentes en el Archivo General de Indias, y él mismo se ofrecía a conseguir una persona que se encargara de ese trabajo, siempre que la Sociedad Chihuahuense de Estudios Históricos consiguiera los fondos necesarios, "unos 5,000 anuales". ${ }^{11}$

A partir de 1970 en que se estableció definitivamente en México, sus visitas a Chihuahua no eran raras, tanto para visitar a sus familiares como por razón de sus actividades como historiador. Entre estas, podemos recordar las siguientes:

El 18 de agosto de 1983 presidió una reunión de sacerdotes y laicos en la ciudad de Chihuahua, con el fin de planear una Historia de la Iglesia en Chihuahua, que había de llevarse a cabo bajo su coordinación. Se llegó a elaborar un proyecto y se dieron los primeros pasos para recabar datos, pero lamentablemente no se le dio continuidad.

El 4 de octubre de 1984 presentó la conferencia "Chihuahua: reflexiones sobre su fundación”, en el Salón de Cabildos de la Presidencia Municipal de Chihuahua.

En diciembre de 1987, Fomento Cultural de Chihuahua le otorgó el premio Tomás Valles Vivar en el área de Ciencias.

De la Nueva Vizcaya, objeto principal de sus investigaciones, tenía una afición particular por la ciudad de sus ancestros, Parral, como lo expresa él mismo en el Prólogo a El nuevo descubrimien-

11 Don José Carlos Chávez le respondió el 12 de septiembre que la Sociedad Chihuahuense de Estudios Históricos había acogido con entusiasmo la iniciativa y que se iba a gestionar ante el Gobierno del Estado la autorización para financiar la obra (Archivo de J. C. Chávez, en el Archivo Histórico de la Arquidiócesis de Chihuahua). 
to de Parral, publicado en $1988^{12}$ y presentado por él mismo en el Salón Rojo del Palacio de Gobierno de Chihuahua:

El tema [de Parral] ha sido uno de mis predilectos a lo largo de casi cincuenta años de investigador, porque en aquel acontecimiento [la fundación de Parral] intervino alguno de mis antepasados y allí se asentó mi familia desde 1632 hasta que los sacudimientos de la Revolución Mexicana la lanzó muy lejos, al extranjero... Pero el Parral me interesaba no sólo por motivos sentimentales sino todavía más por la importancia que tuvo como sede del gobierno provincial, como centro minero que fue ocasión de otras fundaciones y como baluarte contra los indios indómitos desde sus inicios hasta bien entrado el siglo XVIII. En el norte de México jel Parral es historia!

Parral correspondió a sus desvelos, entre otras formas, nombrándolo el 8 de junio de 1988 socio honorario del Patronato Pro Rescate del Archivo Histórico de esa ciudad.

Otros datos sobre el cariño e interés del padre Porras por Chihuahua nos los aporta Chantal Cramaussel (2006):

Se alegró mucho cuando en 1988 la Universidad de Ciudad Juárez lo invitó a participar en el primer congreso de Historia Regional Comparada en Ciudad Juárez, pensaba presentar un trabajo sobre los asentamientos situados entre la Junta de los Ríos (Ojinaga) y Paso del Norte en el siglo XVIII pero la muerte se lo impidió,

y "Uno de sus sueños era fundar el Colegio de Chihuahua en Parral, de donde su familia era originaria y más precisamente en el Palacio de Alvarado que había conocido de niño" (Cramaussel, 2006).

La calidad del doctor Porras como historiador no podía pasar inadvertida para los medios culturales y oficiales de nuestra patria, lo cual se tradujo en una serie impresionante de reconocimientos y de membresías a las más importantes sociedades culturales

12 Buena reseña de esta obra publicó el historiador jesuita Salvador Treviño Castro, "Parral y el Padre Porras Muñoz", en Novedades de Chihuahua, 7 de marzo de 1989. También Jesús Vargas Valdés escribió sobre esta obra y su autor en La Fragua de los Tiempos, El Heraldo de Chihuahua, 16 de junio de 1996. 
relacionadas con su especialidad, como se puede ver en la lista al final de esta reseña.

\section{SU MUERTE}

La salud del doctor Porras Muñoz comenzó a quebrantarse en los últimos años de su vida, sobre todo a causa de problemas cardiovasculares que fueron los que le causaron la muerte el 28 de junio de 1988. Murió mientras realizaba sus habituales tareas sacerdotales, en la residencia del Opus Dei, en la calle Vito Alessio Robles 97, a donde se había mudado pocos años antes. Tenía setenta y un años de edad. Después de una misa de cuerpo presente en la RUP, celebrada por el vicario regional del Opus Dei en México, doctor Rafael Fiol Mateos, sus restos, acompañados de la oración y el aprecio de cientos de amigos, familiares y colegas, fueron depositados en el panteón Español.

Guillermo Porras Muñoz es considerado como uno de los historiadores más relevantes que ha tenido nuestro país, por sus valiosos trabajos de investigación sobre la historia de México durante el periodo colonial. Como estilo personal, todos los que lo trataron más de cerca están de acuerdo en describirlo como una persona sencilla, de trato amable, respetuoso con quienes tenían ideas diferentes, generoso en compartir sus conocimientos, sobre todo con los estudiantes que se iniciaban en la investigación histórica, de un gran sentido práctico, organizado y metódico en su trabajo, y muy firme y coherente en sus convicciones éticas y religiosas. ${ }^{13}$

\section{PARTICIPACIÓN EN CONGRESOS}

Porras Muñoz tuvo la oportunidad de participar en importantes eventos de historia, en algunos de los cuales fue colaborador acti-

13 De las firmes convicciones religiosas de don Guillermo habla esta anécdota de la cual hizo eco, entre otros, su amigo el historiador jimenense Octavio Fernández Perea: cuando el presidente López Portillo iba a entregarle el premio Ciudad de México en 1982, el presidente exigió que el padre Porras se quitara el traje clerical con el que se había presentado. El padre se negó cortésmente y pidió licencia para retirarse. El presidente, asombrado, no solo le entregó el premio sino que le dio una doble felicitación. 
vo, ya sea en su organización o presentando ponencias que luego fueron publicadas:

1. VII Congreso Mexicano de Historia, Guanajuato 1945, del que fue secretario de la Sección de Historia Virreinal.

2. Asamblea de Americanistas, Sevilla, 1948.

3. I Congreso de Historia Hispanoamericana, Madrid, 1949.

4. Congreso de Historia del Noroeste, Monterrey, 1971.

5. IV Congreso del Instituto Internacional de Historia del Derecho Indiano, Morelia, 1975.

6. Encuentro de Estudios Guadalupanos, Villa de Guadalupe, 1977.

7. Primeras Jornadas de Historia del Derecho Patrio, Toluca, 1978.

8. VI Congreso del Instituto Internacional de Historia del Derecho Indiano, Valladolid, España, 1980.

9. III Congreso de Historia del Derecho Mexicano, México, 1983.

10. VI Coloquio de Antropología e Historia Regional, Zamora, Michoacán, 1984.

11. VII Reunión de Historiadores Mexicanos y Norteamericanos, Oaxaca, 1985.

12. I Coloquio de Historia Regional, Pachuca 1986.

13. I Congreso Interamericano del Medio Milenio en América, Cocoyoc, Morelos, 1986.

\section{NOMBRAMIENTOS, MEMBRESÍAS Y DISTINCIONES}

1. Entre 1944 y 1945 fue miembro de la Sociedad Chihuahuense de Estudios Históricos.

2. Junta Mexicana de Investigaciones Históricas. Director del Comité de Publicaciones (1945-1946).

3. El 30 de junio de 1975 ingresó a la Academia Nacional de Historia y Geografía. Presentó como trabajo de ingreso Un golpe de estado contra Hernán Cortés.

4. En 1980 recibió el título de Miembro Emérito de la Sociedad de Historia Eclesiástica Mexicana. 
5. En 1982 se convirtió en miembro del Instituto de Investigaciones Históricas de la Universidad Nacional Autónoma de México.

6. Ese mismo año recibió de manos del presidente de México, José López Portillo, el premio Ciudad de México por su libro El gobierno de la Ciudad de México en el siglo XVI, con el que ganó el concurso sobre la historia de la ciudad, convocado por el Departamento del Distrito Federal.

7. En 1984 fue recibido como miembro del Sistema Nacional de Investigadores, que instituyó ese año la Secretaría de Educación Pública.

8. El 17 de mayo de 1986 se le otorgó en Monterrey la Medalla de Acero al Mérito Histórico “Capitán Alonso de León”, de la Sociedad Neoleonesa de Historia, Geografía y Estadística.

9. El 21 de octubre de 1986 fue recibido como miembro de número en la Academia Mexicana de la Historia, correspondiente de la Real de Madrid, con el sillón n. ${ }^{\circ}$ 4, que había dejado vacante Jesús Silva Herzog y antes de este ocupara el padre Ángel María Garibay K. Su trabajo de ingreso versó sobre El clero secular y la evangelización de la Nueva España. Su ingreso en la Academia Mexicana de la Historia fue, según sus propias palabras, "la culminación de labor como historiador".

10. El 19 de diciembre de 1986, la Real Academia de la Historia de Madrid lo nombró individuo correspondiente.

11. Fue asesor del Consejo del Centro Histórico de la Ciudad de México.

12. En diciembre de 1987, Fomento Cultural de Chihuahua le otorgó el premio Tomás Valles Vivar en el área de Historia.

13. El 8 de junio de 1988 fue nombrado socio honorario del Patronato Pro Rescate del Archivo Histórico de Parral.

14. El 9 de junio de 1988 recibió el Premio Banamex Atanasio G. Saravia de Historia Regional Mexicana, en Durango, con ocasión del centenario de este historiador duranguense. Ese mismo día se le dio un reconocimiento del Grupo Provincia, de Nombre de Dios, Durango. 
15. El 30 de junio de 1989 la Academia Mexicana de la Historia, en colaboración con el Consejo del Centro Histórico de la Ciudad de México, rindió un homenaje a su memoria a un año de su fallecimiento. En el acto participaron los historiadores mexicanos Silvio Zavala, Josefina Muriel, Luis González y González, Guadalupe Pérez San Vicente y Ernesto de la Torre Villar (Excélsior, México, 24 de junio de 1989).

16. Finalmente, en Ciudad Juárez existe una escuela a nivel preescolar con el nombre de Guillermo Porras Muñoz.

\section{A PARTE: BIBLIOGRAFÍA DE GUILLERMO PORRAS MUÑOZ ${ }^{14}$}

Para dar una idea más completa de Guillermo Porras Muñoz como historiador, y como una aportación útil para los investigadores, creí conveniente incluir su bibliografía (en orden cronológico).

\section{ESCRITOS DE HISTORIA}

\section{A Libros}

1. Diario y derrotero de Pedro de Rivera. Paleografía y presentación del texto y notas de GPM. México, distribuido por Librería Porrúa Hnos. y Cía., 1945.

2. Iglesia y Estado en Nueva Vizcaya (1562-1821). Universidad de Navarra, Pamplona, 1966; segunda edición, UnAM, Instituto de Investigaciones Jurídicas, México, 1980.

3. La frontera con los indios de Nueva Vizcaya en el siglo XVII. Fomento Cultural Banamex, México, 1980. Reeditado en Chihuahua por Gobierno del Estado en 2006.

4. El gobierno de la Ciudad de México en el siglo XVI. Libro por el que recibió el premio Ciudad de México en 1982. Publicado por el Instituto de Investigaciones Históricas de la UNAM, México, 1980.

5. El nuevo descubrimiento de San José del Parral. Instituto de Investigaciones Históricas de la unAM, Serie Historia Novohispana n. ${ }^{\circ}$ 39, México, 1988.

14 Confeccionada por Dizán Vázquez. 
6. Personas y lugares en la Ciudad de México. Siglo xvi. Tomo I: Fray Juan de Zumárraga. UNAm: Instituto de Investigaciones Históricas, México, 1988. Antes de morir, dejó preparado el tomo II de esta obra: La Alameda de la Ciudad de México y su entorno urbano durante el periodo virreinal. ${ }^{15}$

7. Haciendas de Chihuahua. Gobierno del Estado de Chihuahua, México, 1993. Obra póstuma realizada con base en diversos textos y apuntes de GPM.

B Folletos

1. El clero secular y la evangelización de la Nueva España. Discurso en su ingreso a la Academia Mexicana de la Historia, octubre de 1986. Respuesta de Roberto Moreno. Publicado en México, 1987.

2. Reflexiones sobre la traza de la Ciudad de México. Publicado por el Consejo del Centro Histórico de la Ciudad de México, 1987.

C Artículos, conferencias y colaboraciones en revistas, periódicos y libros

1. Spanish Horses in Western Planes. En la revista Southwest, El Paso, Texas, septiembre de 1934.

2. Indian Warfare. En Southwest, El Paso, Texas, enero de 1935.

3. The Oñate Expedition at the Rio Grande. En Southwest, El Paso, Texas, abril de 1935.

4. The Guadalupe Mision. En Southwest, El Paso, Texas, febrero de 1936.

5. The Ancient Fortress. En Southwest, El Paso, Texas, julio de 1937.

6. Probanza con motivo del incidente que provocó la llegada de Cristóbal de Tapia, año de 1522. En Boletín del Archivo General de la Nación, 1938.

15 Dejó también inédito El temor a los indios y la fortificación de México. 
7. La destrucción de un archivo. En Divulgación Histórica, T. II, n. ${ }^{\circ}$ 10, México, 1941.

8. Cristóbal de Tapia, año de 1522. En Boletín del Archivo General de la Nación, México, 1941.

9. Fr. Alonso de la Oliva. En Divulgación Histórica, T. II, n. ${ }^{\circ}$ 12, México, 15 de octubre de 1941.

10. Don Francisco Gómez de Mendiola y Solórzano, tercer obispo de Nueva Galicia. En Divulgación Histórica, año III, n. ${ }^{\circ} 11$, México, 1942.

11. Los archivos de Durango. En Divulgación Histórica, T. iv, n. ${ }^{\circ}$ 5, México, 1943.

12. El primer reloj de la parroquia, actual Catedral de Chihuahua. En Revista Chihuahua, marzo de 1944.

13. Una operación quirúrgica en Chihuahua en 1793. En Revista Chihuahua, abril de 1944.

14. Un apache en Morelia. En Revista Chihuahua, junio de 1944.

15. Los insurgentes en Ciudad Jiménez. En Revista Chihuahua, julio de 1944.

16. La emboscada de Baján. En Revista Chihuahua, septiembre de 1944.

17. Los apaches a fines del siglo xvIII, según un manuscrito de Antonio Cordero y Bustamante. Introducción y notas por GPM. En Boletín de la Sociedad Chihuahuense de Estudios Históricos, T. v, n. ${ }^{\circ}$ 3, 4 y 5, marzo, abril y mayo; junio; y julio de 1945.

18. Una paz con los tobosos. En Boletín de la Sociedad Chihuahuense de Estudios Históricos, T. v, n. ${ }^{\circ}$ 7, Chihuahua, diciembre de 1945.

19. Acta de matrimonio de Bernardo de Gálvez y Felicitas Saint Maxent. En Boletín del Archivo General de la Nación, T. xvi, n. ${ }^{\circ}$ 2, México, 1945.

20. Inventarios de las misiones jesuitas en el estado de Chihuahua. Documentos presentados por GrM. En Boletín de la Sociedad Chihuahuense de Estudios Históricos, T. v, n. ${ }^{\circ}$ 8, 20 de enero de 1946. 
21. Origen de Saucillo. En Boletín de la Sociedad Chihuahuense de Estudios Históricos, T. v, n. ${ }^{\circ}$ 12, Chihuahua, junio-julio de 1946.

22. Datos sobre la fundación de ciudad Jiménez. En Boletín de la Sociedad Chihuahuense de Estudios Históricos, T. vi, n. ${ }^{\circ}$, agosto-septiembre de 1946.

23. Fray Pedro de Espinareda, inquisidor de Nueva Vizcaya. En Memorias de la Academia Mexicana de la Historia, T. v, n. ${ }^{\circ}$ 3, México, 1946.

24. Las tropas de El Paso en 1684. En Boletín de la Sociedad Chihuahuense de Estudios Históricos, T. vI, n. ${ }^{3}$, Chihuahua, enero de 1947.

25. Los vecinos del Valle de San Bartolomé en 1604. En El Correo de Parral, 9 de abril de 1947.

26. Los franciscanos en San José del Parral. La ermita de San Antonio. En El Correo de Parral, 7 de junio de 1947.

27. Viaje a Méjico del marqués de Montes Claros y Advertencias para su gobierno. En Revista de Indias, n. ${ }^{\circ}$ 27, Madrid, 1947.

28. Martín López, carpintero de Ribera. En Revista de Indias, n. ${ }^{\circ}$ 31-32, Madrid, 1948.

29. Un capitán de Cortés: Bernardino Vázquez de Tapia. En Anuario de Estudios Americanos, T. v, Sevilla, 1948.

30. El indio en México. En Cuadernos Hispanoamericanos, n. ${ }^{\circ}$, Madrid, 1948.

31. El título de la ciudad de Durango. En Memorias de la Academia Mexicana de la Historia, T. vII, n. ${ }^{\circ}$ 2, México, 1948.

32. Mexicanos en España. En Estudios Americanos, T. I, n. ${ }^{\circ} 1$, Sevilla, 1948.

33. Bernardo de Gálvez. En Miscelánea Americanista. Memorias del I Congreso de Historia Hispanoamericana, T. III, Madrid, 1952.

34. Nuevos datos sobre Bernardo de Balbuena. En Revista de Indias, n. ${ }^{\circ}$ 42, Madrid, 1952.

35. Las minas de Chihuahua. En Boletín del Archivo General de la Nación, Segunda Serie, T. vII, n. ${ }^{\circ}$ 3, México, 1966. 
36. Don Marcos de Torres y Rueda y el gobierno de la Nueva España. En Anuario de Estudios Americanos, T. xxII, Sevilla, 1966.

37. Diego de Ibarra y la Nueva España. En Estudios de Historia Novohispana, Vol. II, México, 1968.

38. El fracaso de Guarico. En Anuario de Estudios Americanos, T. xxvi, Sevilla, 1969.

39. La calle de la Cadena en México. En Estudios de Historia Novohispana, Vol. v, México, 1974.

40. Prólogo. En Historia de Durango, 1563-1910, de José Ignacio Gallegos. Edición del autor, México, 1974.

41. La integración de los oficios del cabildo de la Ciudad de México entre 1524 y 1540. En Anuario Jurídico de la UNAM, III-IV, México, 1976-1977.

42. Un golpe de Estado contra Hernán Cortés. Conferencia presentada con ocasión de su ingreso en la Academia Nacional de Historia y Geografía, en 1975. Publicada en la Revista Humanitas, Monterrey, 1978.

43. Fuentes para la investigación de la historia del derecho en Hidalgo del Parral y Chihuahua. En Memorias del I Congreso de Historia del Derecho Mexicano, México, 1981.

44. La proyección de la sede mexicana. En Gaceta Oficial del Arzobispado de México, T. xxII, n. 9-10, México, 1982.

45. La fusión de la factoría y la veeduría de la Real Hacienda de México. En Memorias del III Congreso de Historia del Derecho Mexicano, México, 1984.

46. La provisión de gobernadores interinos de Nueva Vizcaya. En Estructura, Gobierno y Agentes de Administración en la América Española, Valladolid, 1984. Publicado también en Revista Encuentro, de El Colegio de Jalisco, n. ${ }^{\circ}$ 7, Guadalajara, 1985.

47. Parral: pueblo minero y frontera de indios. Conferencia presentada en la VII Reunión de Historiadores Mexicanos y Norteamericanos, Oaxaca, 23-26 de octubre de 1985.

48. Alonso de Villaseca, el rico. En I Coloquio de Historia Regional. Memoria, Pachuca, 1986. 
49. El regio patronato indiano y la evangelización. Conferencia presentada en el I Congreso Interamericano del Medio Milenio en América, en Cocoyoc, Morelos, en 1986, y publicada en Scripta Theologica, Revista de la Facultad de Teología de la Universidad de Navarra, Vol. xIx, Fasc. 3, septiembre-diciembre de 1987.

50. Introducción y cronología. En Crónica de la Revolución Mexicana (1910-1929), de Marcelo Caraveo. Presentación y notas de Jean-Pierre Bastian. Editorial Trillas, Colección Linterna Mágica, 19, México, 1987.

51. Comentario. En Recopilación de leyes de los reinos de las Indias. Estudios histórico-jurídicos. Varios autores. Miguel Ángel Porrúa en coedición con la Escuela Libre de Derecho, México, 1987.

52. Nombre de Dios, Durango. Conferencia en la recepción del premio Banamex Atanasio G. Saravia, Durango, el 9 de junio de 1988. Publicado en el folleto conmemorativo del evento, Centenario de Atanasio G. Saravia, México, 1989.

53. Chihuahua: reflexiones sobre su fundación. Conferencia pronunciada el 4 de octubre de 1984 en el Salón de Cabildos de la Presidencia Municipal de la ciudad de Chihuahua. Publicada con el título "La fundación de Chihuahua" por Cuadernos del Norte, noviembre-diciembre de 1989.

54. Hace doscientos años: "México llorosa...". En Revista del Instituto de Investigaciones Históricas, Vol. 10, unAm, México, 1991.

Poco antes de su fallecimiento, Guillermo Porras Muñoz escribió también, por lo menos, los siguientes artículos, pero no tenemos los datos de su publicación:

1. El mayorazgo Dávila.

2. La situación jurídica del Colegio de las Vizcaínas.

3. El cabildo en la república de españoles.

4. Algunas procuraciones de la Nueva España a la Corte de Castilla. 
5. Parral: centro minero y frontera de indios.

6. Acumulaciones y compilaciones jurídicas del cabildo de la Ciudad de México.

\section{ESCRITOS SOBRE OTROS TEMAS}

\section{A Libros}

1. La devoción a San José. Selección e introducción de textos de Pío IX, León XIII y Benedicto XVI. Editora de Revistas, Colección Mi-Nos, México, 1972.

2. Pecado y penitencia. Editora de Revistas, Colección Mi-Nos, México, 1974.

B Artículos

1. El contra-anuncio. En Istmo, n. ${ }^{\circ} 62,1969$.

2. Esdai. Oportunidad para la mujer. En Istmo, n. ${ }^{\circ}$ 65, noviembre-diciembre de 1969. Publicado también como separata.

3. La Navidad en México. En Istmo, n. ${ }^{\circ} 71$, México, noviembrediciembre de 1970.

4. Introducción al libro: Luis Rubio, Letra que cantaron los ángeles. Historia y símbolos de la Navidad mexicana, México, 1971.

5. De México a Chihuahua por mar. En Istmo, n. ${ }^{\circ}$ 72, México, enero-febrero de 1971.

6. ¡Viva el pecado! En Istmo, n. ${ }^{\circ}$ 73, México, marzo-abril de 1971.

7. Niños contentos y padres traumatizados. En Istmo, n. ${ }^{\circ} 74$, México, mayo-junio de 1971.

8. Lo mexicano por dentro y por fuera. En Istmo, n. ${ }^{\circ}$ 75, México, julio-agosto de 1971.

9. ¿Qué está leyendo? En la revista Giro, n. ${ }^{\circ} 00,1976$. Publicado también en SEDS, n. ${ }^{\circ} 41$.

10. El alambrito: símbolo de improvisación. En Giro, n. ${ }^{\circ} 1,1976$.

11. Viaje en autobús. En Giro, n. ${ }^{\circ}$ 3, 1977.

12. La vida en México... vista por Guillermo Porras Muñoz. En Istmo, n. ${ }^{\circ} 113,1977$.

13. El Congreso Catequístico Internacional. En SEDS, n. ${ }^{\circ} 4$.

14. Alguien está enojado con los santos. En SEDS, n. ${ }^{\circ} 27$. 
15. ¡No serviré! En SEDS, n. ${ }^{\circ} 66$.

16. ¿Ha muerto monseñor Escrivá de Balaguer? En SEDS, número especial, México, julio de 1975.

17. La virtud de la hospitalidad. En SEDS, n. ${ }^{\circ} 78$.

18. Jezabel hoy. En SEDS, n. ${ }^{\circ} 82$.

19. La Navidad... ¿de quién? En SEDS, n. ${ }^{\circ} 88$.

20. ¡Eres polvo! Cuaresma. En SEDS, n. ${ }^{\circ} 93$.

21. A sólo dos años... En SEDS, n. ${ }^{\circ} 101$.

22. El escapulario de la Virgen del Carmen. En SEDS, n. ${ }^{\circ} 126$.

Guillermo Porras Muñoz fue durante varios años colaborador en la Sección Bibliográfica de la Revista de Historia de América. Contribuyó también con varios artículos para The New Catholic Encyclopedia, Washington, DC, 1965-1967. Como profesor impartió numerosos cursos de teología en la Universidad Panamericana.

\section{FUENTES DE CONSULTA}

Álvarez, S. (1989). Un gran historiador chihuahuense. El padre Guillermo Porras Muñoz (1917-1988). Ahora. Ciudad Juárez. Publicado también, revisado, en Raíces, 9. Ciudad Juárez, agosto-septiembre de 1990.

Cárdenas Gutiérrez, S. (2006, 3 de febrero). Guillermo Porras Muñoz, historiador del derecho. Conferencia presentada en el Homenaje a Guillermo Porras Muñoz organizada por la Unidad de Estudios Históricos y Sociales de la UACJ.

Cramaussel, C. (2006, 3 de febrero). La obra de Guillermo Porras Muñoz y la historiografía colonial del norte de México. Conferencia presentada en el Homenaje a Guillermo Porras Muñoz organizada por la Unidad de Estudios Históricos y Sociales de la UACJ.

Cuatro chihuahuenses reciben el premio Tomás Valles 1987. El Heraldo de Chihuahua, 8 de noviembre de 1987.

De la Torre Villar, E. (1988). El hombre y el historiador. Guillermo

Porras Muñoz. Historia Mexicana, 38(2), octubre-diciembre, 407-409. 
Derbez García, E. (1986, 19 de mayo). Sociedad de Historia cumple XLIV aniversario. El Diario de Monterrey.

El doctor Guillermo Porras Muñoz ingresó a la Academia Mexicana de Historia. Gaceta UNAM. México, 27 de octubre de 1986.

Enríquez, M. A. (1986, 22 de octubre). Guillermo Porras, miembro de la Academia Mexicana de Historia. El Universal. México.

Entrevistas del autor (febrero-marzo de 2006) con: Sra. Rosalía

Porras de Acosta; Sra. Beatriz Acosta de Caraveo; Lic. Manuel Porras Abud; Sr. Mario González Múzquiz; don José González Múzquiz; Ing. J. Roberto Durán; Dra. Josefina Muriel de González Mariscal.

Falleció el reconocido sacerdote historiador Guillermo Porras Muñoz. Novedades de Chihuahua, 30 de junio de 1988.

Falleció el Dr. Guillermo Porras, Pbro., miembro de la Academia Mexicana de Historia. Boletín DIC de la Cemidac. México, 18 de agosto de 1988.

Familia Porras Muñoz (2009, 3 de mayo). Galería de fotos en El Heraldo de Chihuahua.

Fernández Perea, O. (1988). Chihuahuenses distinguidos. El padre Guillermo Porras Muñoz. El Heraldo de Chihuahua.

Foto y nota sobre la entrega del premio Ciudad de México al Dr. Porras Muñoz por parte del presidente López Portillo. El Heraldo de México, 25 de noviembre de 1982.

Guillermo Porras Muñoz, Joaquín A. Chacón y Anthony Quinn, premios Tomás Valles '87. Novedades de Chihuahua, 7 de septiembre de 1987.

Guillermo Porras. Norte de Chihuahua, 1986.

Guillermo Porras Muñoz. Reseña biográfica. Personajes de Chihuahua, INEA/Gobierno del Estado de Chihuahua, 1992.

Homenaje a Guillermo Porras Muñoz, el 30. Excélsior. México, 24 de junio de 1989.

Márquez Terrazas, Z. (2006). El padre Guillermo Porras Muñoz. Boletín UEHS. Chihuahua, enero-febrero.

(1986, 2 de julio). El sillón de don Jesús. El Heraldo de Chihuahua. 
Muere el P. Guillermo Porras en México. Notidiócesis. Chihuahua, 10-16 de julio de 1988.

Muriel de la Torre, J. Guillermo Porras Muñoz (1917-1988), Academia Mexicana de Historia. Recuperado en abril de 2018, de https://web.archive.org/web/20120307204044/http://www.acadmexhistoria.org.mx/miembrosANT/res_guillermo_porras.pdf

Murió el historiador chihuahuense Guillermo Porras Muñoz en el D. F. Norte de Chihuahua, 30 de junio de 1988.

Murió el sacerdote Guillermo Porras, uno de los historiadores más relevantes de nuestro país. El Heraldo de México, 4 de julio de 1988.

Payán Franco, H. (1987, 27 diciembre/1988, 3 de enero). Histórica conferencia del doctor Guillermo Porras Muñoz. Ágora, de Novedades de Chihuahua.

Porras Muñoz, Guillermo. Diccionario Porrúa. Historia, biografía y geografía de México (6. ${ }^{a}$ ed.). México, 1995.

Porras Muñoz, Guillermo. Enciclopedia de México, edición digital, 2002.

Porras Muñoz, G. (1975, julio). ¿Ha muerto monseñor Escrivá de Balaguer? SEDS (Servicio Especial de Informaciones), número especial. México.

Rodríguez Balderas, R. (2009). Don Guillermo Porras Muñoz (19171988), a los 20 años de su fallecimiento. Breve semblanza de un connotado historiador. Historia desconocida. Una aportación a la historia de la Iglesia en México. Libro anual 2008 de la Sociedad Mexicana de Historia Eclesiástica, A. C. México: Minos III Milenio Editores.

Ruiz Velasco N., I. (1988, 17 de agosto). Falleció el doctor Guillermo Porras Muñoz, miembro de la Academia Mexicana de Historia. Novedades de México. Reproducido en el Boletín DIC de la Cemidac. México, 18 de agosto de 1988.

Saravia de Farrés, A. G. (1989). Semblanza del doctor Guillermo Porras Muñoz. Con ocasión de la entrega del premio Banamex Atanasio G. Saravia, en Durango, 9 de junio de 1988. Publicada en el folleto Centenario de Atanasio G. Saravia. México. 
Tena Antillón, B. (1992). Guillermo Porras Muñoz. Personajes de Chihuahua. Chihuahua: INEA.

Treviño, S. Del Chihuahua colonial: Parral y el padre Porras Muñoz. Novedades de Chihuahua, 7 de marzo de 1989; y en Siete, suplemento cultural de Novedades de Chihuahua, 9 de marzo de 1989 / Del Chihuahua colonial: La familia Porras. Novedades de Chihuahua, 15 de agosto de 1989; y en Siete, suplemento cultural de Novedades de Chihuahua, 17 de agosto de 1989 / Don Guillermo Porras Muñoz. In memoriam. Siete, suplemento cultural de Novedades de Chihuahua, 30 de noviembre de 1989.

Vargas Valdez, J. Don Guillermo Porras Muñoz y el nuevo descubrimiento de San José del Parral. La Fragua de los Tiempos, de El Heraldo de Chihuahua, 16 de junio de 1996. 